\title{
Non-granular laterally spreading tumors: potential superficial cancers that artificial intelligence does not easily detect
}

Artificial intelligence (AI) and especially deep learning have recently shown promising results in various medical fields involving endoscopic images [1, 2]. However, as Al becomes more and more powerful, we must remain careful and attentive in detection. We showed recently in a case report that a real-time computeraided detection system (CADe) may have difficulties in detecting flat colorectal sessile serrated adenomas/polyps (SSA/ Ps) [3]. Among the difficult lesions to detect, non-granular laterally spreading tumors (LST-NGs) represent a challenge because, in addition to their flat macroscopic form, which is difficult to identify, they are associated with advanced histology, with $27 \%$ of invasive cancers being found in the elevated non-granular forms and $47 \%$ in the pseudodepressed ones [4]. It is therefore a major challenge for diagnostic endoscopy that these are not missed, as they are potential interval cancers that will have become advanced by the next surveillance colonoscopy 3 or 5 years later.

We therefore aimed to assess the efficiency of a recent CADe system to identify LST-NGs, using the ENDO-AID software in combination with the EVIS X1 video column (Olympus, Tokyo, Japan).

We herein report three patients with LSTNG lesions measuring more than $4 \mathrm{~cm}$ each that were not correctly detected by

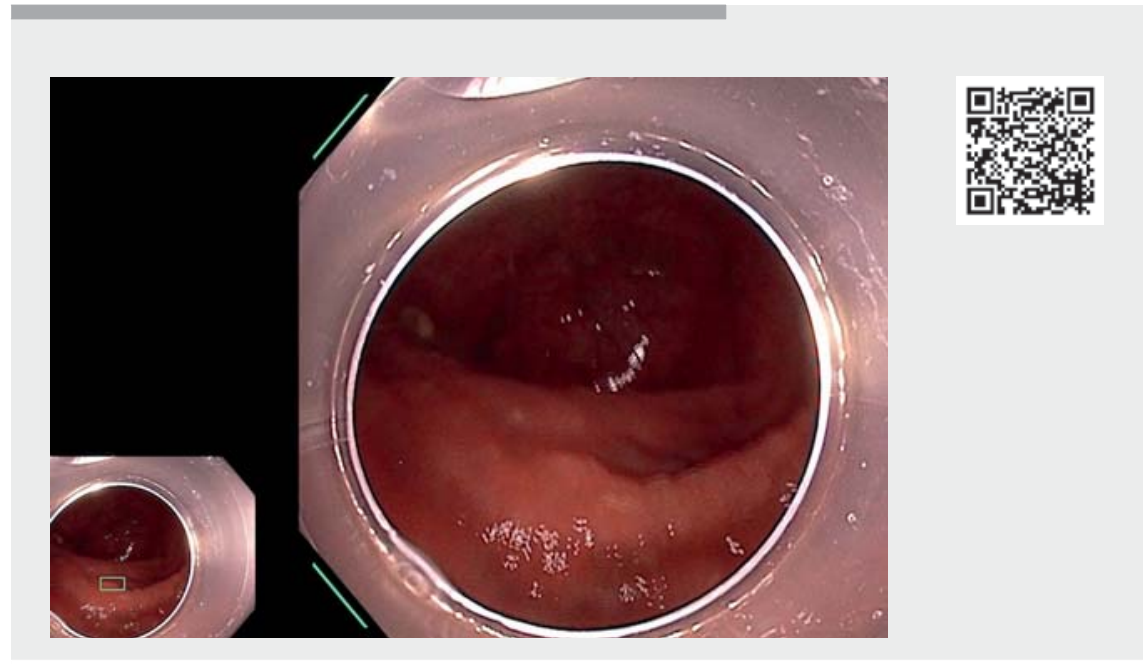

$\checkmark$ Video 1 Endoscopic diagnosis of non-granular laterally spreading tumors (LST-NGs) that were not correctly identified by the CADe system.

CADe ( Video 1 ). Because of their less visible edges, it seems that the tested CADe system is sometimes not sufficiently efficient in identifying the flat shape of these lesions, resulting in incomplete detections and false positives ( $\mathbf{F i g} \mathbf{1} \mathbf{1}$ ).

These cases illustrate that potential superficial cancers, such as LST-NGs or SSA/Ps, can still be hard to detect, even with a recently developed CADe system. Deep learning algorithms have to be trained further to detect these rare lesions, which can in practice be hard to detect with the human eye, and for which CADe assistance would be extremely valuable.

Endoscopy_UCTN_Code_CCL_1AD_2AB

\section{Competing interests}

The authors declare that they have no conflict of interest.
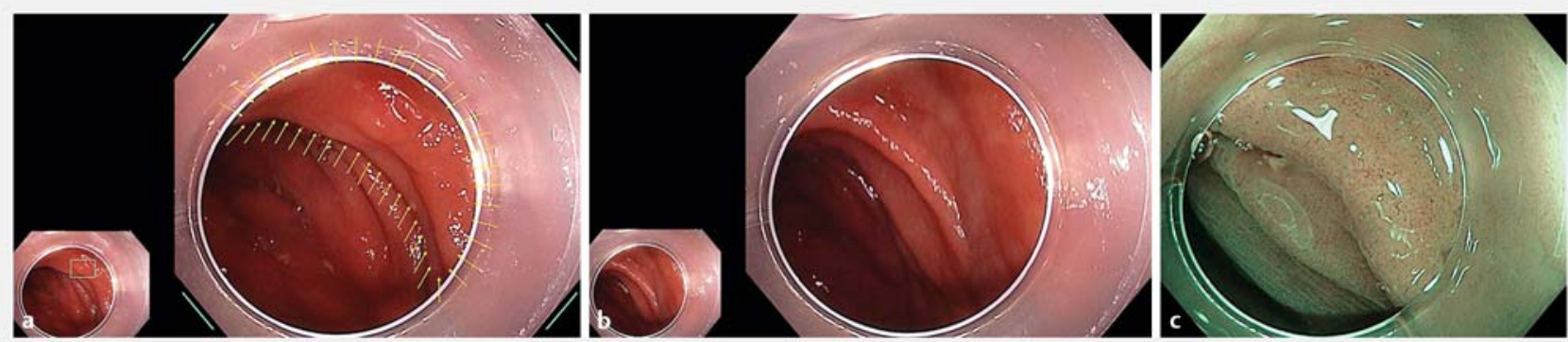

- Fig. 1 Views of the same laterally spreading tumor on: a white-light endoscopy, with the CADe screen shown in the lower left corner showing the CADe detection area (green rectangle) and the real boundaries of the lesion (yellow arrows); $\mathbf{b}$ white-light endoscopy with no detection by CADe; $c$ narrow-band imaging. 
Pierre Lafeuille ${ }^{1}$, Jérôme Rivory ${ }^{1}$, Thomas Lambin ${ }^{1}$, Clara Yzet ${ }^{2}$, El Houcine Latif ${ }^{3}$, Adrien Bartoli $^{4}$, Mathieu Pioche ${ }^{1}$

1 Department of Endoscopy and Hepatogastroenterology, Edouard Herriot Hospital, Lyon, France

2 Department of Endoscopy and Hepatogastroenterology, Amiens University Hospital, Amiens, France

3 Yansys Medical, Vichy, France

4 EnCoV, Institut Pascal, UMR 6602, CNRS/ UCA/CHU, Clermont-Ferrand, France

\section{Corresponding author}

\section{Pierre Lafeuille, MD}

Endoscopy unit - Digestive Disease department, Pavillon L - Edouard Herriot Hospital, 69437 Lyon, France pierre.lafeuille@chu-lyon.fr
[1] Aoki T, Yamada A, Aoyama K et al. Automatic detection of erosions and ulcerations in wireless capsule endoscopy images based on a deep convolutional neural network. Gastrointest Endosc 2019; 89: 357-363.e2

[2] de Groof A], Struyvenberg MR, Fockens KN et al. Deep learning algorithm detection of Barrett's neoplasia with high accuracy during live endoscopic procedures: a pilot study (with video). Gastrointest Endosc 2020; 91 : 1242-1250

[3] Lafeuille P, Lambin T, Yzet C et al. Flat colorectal sessile serrated polyp: an example of what artificial intelligence does not easily detect. Endoscopy 2021. doi:10.1055/a1486-6220

[4] Yamada M, Saito Y, Sakamoto T et al. Endoscopic predictors of deep submucosal invasion in colorectal laterally spreading tumors. Endoscopy 2016; 48: 456-464
Bibliography

Endoscopy 2022; 54: E494-E495

DOI 10.1055/a-1640-8624

ISSN 0013-726X

published online 8.10 .2021

(c) 2021. Thieme. All rights reserved.

Georg Thieme Verlag KG, Rüdigerstraße 14,

70469 Stuttgart, Germany

\section{ENDOSCOPY E-VIDEOS}

https://eref.thieme.de/e-videos

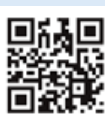

Endoscopy E-Videos is an open access online section, reporting on interesting cases and new techniques in gastroenterological endoscopy. All papers include a high quality video and all contributions are freely accessible online. Processing charges apply (currently EUR 375), discounts and wavers acc. to HINARI are available.

This section has its own submission website at https://mc.manuscriptcentral.com/e-videos 